\title{
Subcutaneous emphysema and ultrasound sonography
}

Toshi Kubodera ${ }^{1}$, Yushi U Adachi² ${ }^{*}$, Toshiyuki Hatano ${ }^{3}$, Tadashi Ejima ${ }^{3}$, Atsushi Numaguchi ${ }^{3}$ and Naoyuki Matsuda ${ }^{3}$

\begin{abstract}
Subcutaneous emphysema is not a rare complication in intensive care unit patients. Recently, ultrasound guidance for central venous puncture is becoming popular; however, the information on imaging for subcutaneous emphysema is limited. We encountered a patient complicated with severe pneumomediastinum and subsequent subcutaneous emphysema. The catheter replacement was attempted, and we examined the visuality of cervical vessels using ultrasound sonography before the intervention. Internal jugular vein itself was observed despite of subcutaneously migrated air bubble; however, the range of ultrasound image was limited, and the relationship between the vessel and the adjacent tissue was unclear.
\end{abstract}

Keywords: Subcutaneous emphysema, Ultrasound sonography, Central venous catheterization

\section{Findings}

Subcutaneous emphysema is not a rare complication in patients admitted to intensive care unit and received mechanical ventilation as well as with pneumomediastinum [1]. High positive end-expiratory pressure leading to excess airway strain would be one of the risk factors of the complications [2]. Patients requiring high airway pressure might be severely ill and need many medical interventions including central venous catheterization.

Recently, ultrasound guidance for central venous puncture is strongly recommended [3] and is sometimes required as a mandatory procedure [4] in hospitals. Ultrasound sonography is a useful and powerful tool for detecting the deep vein distinguished from the artery using the color Doppler imaging methods [5]. Moreover, sonography enables us to confirm the site of puncture for monitoring the spatial relationships between the venous and the needle during the puncture through the real-time imaging [6]. One of the important factors for complicating the ultrasoundguided central venous catheterization is subcutaneous emphysema as ultrasound barrier [7]. Absolute difference of acoustic impedance between the aqueous tissue and migrated air causing emphysema occludes the scattering of ultrasound signals and prevents from composing the image of deep body structures. Verniquet and Katel [7] reported the scanning image of the patient with subcutaneous emphysema; however, there is scarce information of the ultrasound images in a literature for the patient with subcutaneous emphysema.

We encountered a patient complicated with severe pneumomediastinum and subsequent subcutaneous emphysema in the intensive care unit (Figure 1). A 56-yearold female patient with adrenal insufficiency followed by severe sepsis and heart failure was required mechanical ventilation with high positive end-expiratory pressure for acute respiratory distress syndrome.

Although the central venous catheter was already placed at admittance to the intensive care unit, replacement of the catheter was indispensable and planned for the long-term treatment. Repeated septic state and chronic infection also required the temporal removal of catheters. Thus, we examined the visuality of cervical vessels using ultrasound sonography before the intervention. In the case, internal jugular vein itself was observed despite of subcutaneously migrated air

\footnotetext{
* Correspondence: yuadachi@med.nagoya-u.ac.jp

${ }^{2}$ Department of Emergency Medicine, Nagoya University Hospital,

65 Tsurumai-cho, Showa-ku, Nagoya, Aichi 466-8550, Japan

Full list of author information is available at the end of the article
} 


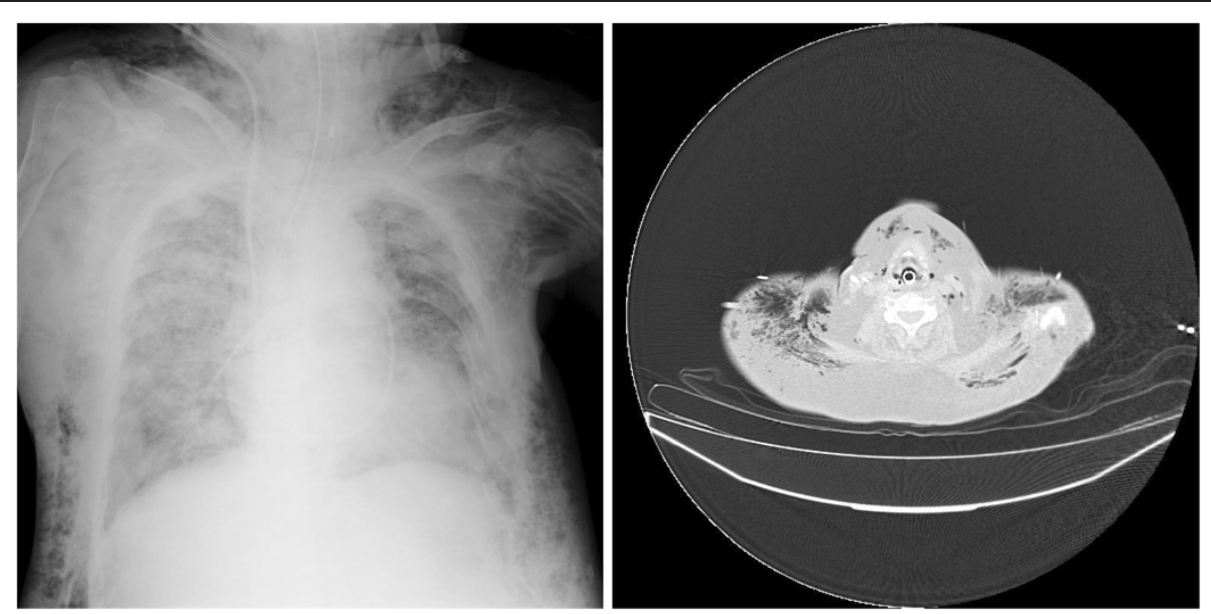

Figure 1 The chest X-ray and CT findings of the patient. Massive emphysema was observed in the neck, chest, and mediastinum.

bubble; however, the range of ultrasound image was limited, and the relationships between the vessel and the adjacent tissue was unclear (Figure 2, left). Moreover, the ultrasound image of carotid artery was vague using long-axis in-plane approaches (Figure 2, right). The latter limitation could cause it difficult to detect an unexpected carotid puncture during central venous catheterization and following misplacement of thin guidewire into the artery $[3,6]$. Subclavian approach was impossible because of the emphysema, and the access of femoral vein was considered as inappropriate because of the necessity of other blood accesses for renal replacement therapy. The catheter replacement was postponed until the clear imaging and safety access by ultrasound guidance was confirmed.

More and more information are gathered for reliable and safety catheterization using ultrasound guidance in the area of anesthesiology and intensive care medicine. We should continue to accumulate information of a plenty of images through daily clinical settings not only for normal subjects but also for complicated cases.
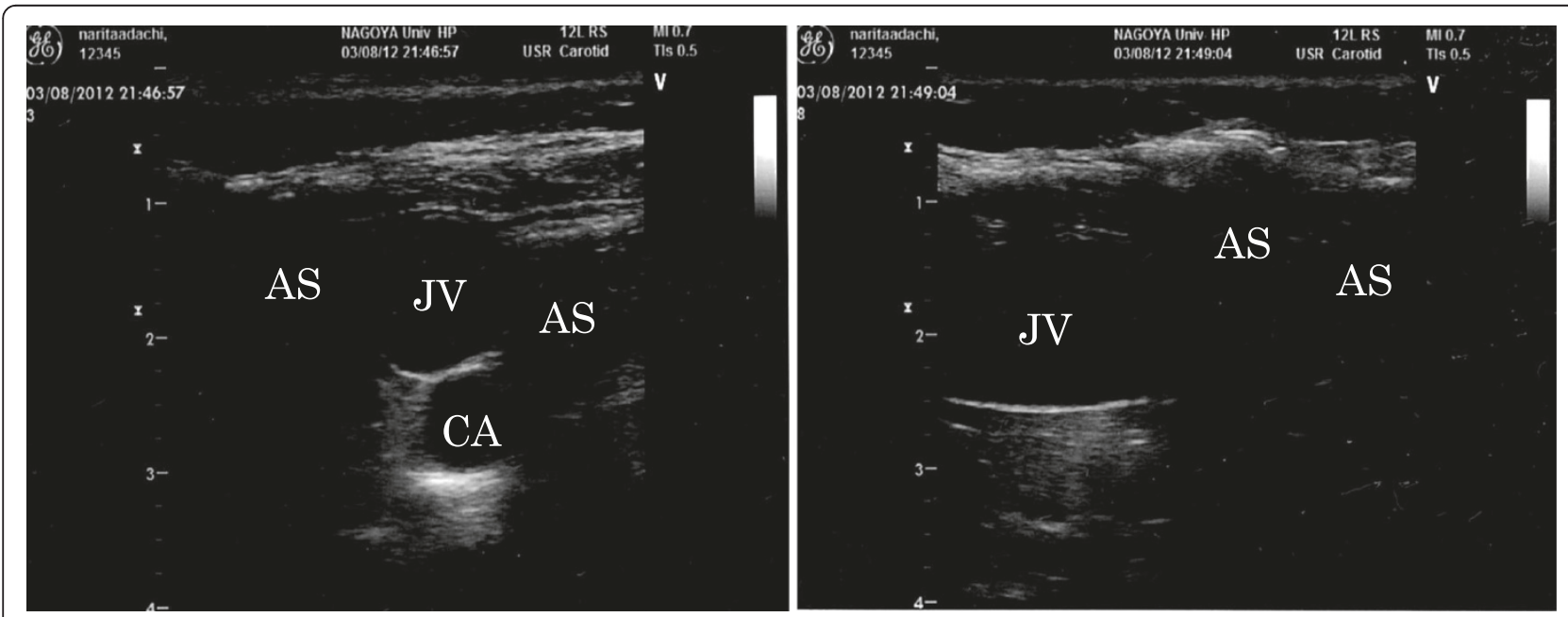

Figure 2 Ultrasound images. Left: The ultrasound image of the patient's neck in coronal view was demonstrated. The identification of both jugular vein and carotid artery was barely possible in spite of many subcutaneous ultrasound barriers by emphysema. Right: The ultrasound image in sagittal view was demonstrated. The jugular vein was feasibly observed; however, the carotid artery that is a relatively deep structure could not be identified. JV jugular vein, CA carotid artery, AS acoustic shadow by air. 


\section{Competing interests}

The authors declare that they have no competing interests.

\section{Authors' contributions}

TK is the chief physician for the patient and decided all clinical practices. YUA recorded the ultrasound image and wrote the manuscript. TH, TE, and AN analyzed the images and revised the letter. NM submitted the letter. All authors read and approved the final manuscript.

\section{Authors' information}

TK is a staff in the Emergency Department of Ogaki Municipal Hospital. He worked in the Department of Emergency and Critical Care Medicine, Nagoya University Graduate School of Medicine. YUA is an assistant professor in the Department of Emergency Medicine and the corresponding author of this letter. TH and TE are assistant professors of Emergency and Critical Care Medicine and consultants of ultrasound sonography. AN is an assistant professor of Emergency and Critical Care Medicine and a consultant of ultrasound echocardiography. NM is a professor and Chairman of Emergency and Critical Care Medicine.

\section{Author details}

'Department of Emergency Medicine, Ogaki Municipal Hospital, Ogaki, Gifu 503-8502, Japan. ${ }^{2}$ Department of Emergency Medicine, Nagoya University Hospital, 65 Tsurumai-cho, Showa-ku, Nagoya, Aichi 466-8550, Japan.

${ }^{3}$ Department of Emergency and Critical Care Medicine, Nagoya University Graduate School of Medicine, 65 Tsurumai-cho, Showa-ku, Nagoya, Aichi 466-8550, Japan.

Received: 2 August 2013 Accepted: 16 October 2013

Published: 27 November 2013

\section{References}

1. Lai Jl, Lin PC, Wang WS, Chang SC, Lai YC: Barotrauma related extensive pneumothorax, pneumomediastinum, and subcutaneous emphysema in a patient with acute respiratory distress syndrome with low tidal volume. Postgrad Med J 2010, 86:567-568.

2. Boussarsar M, Thierry G, Jaber S, Roudot-Thoraval F, Lemaire F, Brochard L: Relationship between ventilatory settings and barotrauma in the acute respiratory distress syndrome. Intensive Care Med 2002, 28:406-413.

3. Tokumine J, Lefor AT, Yonei A, Kagaya A, Iwasaki K, Fukuda Y: Three-step method for ultrasound-guided central vein catheterization. $\mathrm{Br} J$ Anaesth 2013, 110:368-373.

4. Neustein SM: Mandating ultrasound usage for internal jugular vein cannulation. Can J Anaesth 2010, 57:868-869.

5. Walther ND, Auyong DB: Subclavian artery and vein transposition has implications for regional anesthesia and subclavian vein catheter insertion. Anesth Analg 2012, 115:211-212.

6. Adachi YU, Tuzuki M, Matsuda N: Is it constantly possible to penetrate only the anterior vessel wall against hydrostatic strain? Crit Care Med 2012, 40:2534-2535.

7. Verniquet A, Kakel R: Subcutaneous emphysema: ultrasound barrier. Can J Anaesth 2011, 58:336-337.

\section{doi:10.1186/2052-0492-1-8}

Cite this article as: Kubodera et al:: Subcutaneous emphysema and ultrasound sonography. Journal of Intensive Care 2013 1:8.

\section{Submit your next manuscript to BioMed Central and take full advantage of:}

- Convenient online submission

- Thorough peer review

- No space constraints or color figure charges

- Immediate publication on acceptance

- Inclusion in PubMed, CAS, Scopus and Google Scholar

- Research which is freely available for redistribution 